\title{
Novel Terthiophene-Substituted Fullerene Derivatives as Easily Accessible Acceptor Molecules for Bulk-Heterojunction Polymer Solar Cells
}

\author{
Filippo Nisic, ${ }^{1}$ Alessia Colombo, ${ }^{1}$ Claudia Dragonetti, ${ }^{1}$ Alessandra Cominetti, ${ }^{2}$ \\ Andrea Pellegrino, ${ }^{2}$ Nicola Perin, ${ }^{2}$ Riccardo Po, ${ }^{2}$ and Alessandra Tacca ${ }^{2}$ \\ ${ }^{1}$ Department of Chemistry, University of Milan, UdR dell'INSTM, Via Golgi 19, 20133 Milan, Italy \\ ${ }^{2}$ Research Center for Non-Conventional Energies, "Istituto Eni Donegani," Eni S.p.A., Via Fauser 4, 28100 Novara, Italy \\ Correspondence should be addressed to Alessia Colombo; alessia.colombo@unimi.it and \\ Andrea Pellegrino; andrea.pellegrino@eni.com
}

Received 26 March 2014; Accepted 8 June 2014; Published 10 July 2014

Academic Editor: Przemyslaw Rupnowski

Copyright (C) 2014 Filippo Nisic et al. This is an open access article distributed under the Creative Commons Attribution License, which permits unrestricted use, distribution, and reproduction in any medium, provided the original work is properly cited.

\begin{abstract}
Five fulleropyrrolidines and methanofullerenes, bearing one or two terthiophene moieties, have been prepared in a convenient way and well characterized. These novel fullerene derivatives are characterized by good solubility and by better harvesting of the solar radiation with respect to traditional PCBM. In addition, they have a relatively high LUMO level and a low band gap that can be easily tuned by an adequate design of the link between the fullerene and the terthiophene. Preliminary results show that they are potential acceptors for the creation of efficient bulk-heterojunction solar cells based on donor polymers containing thiophene units.
\end{abstract}

\section{Introduction}

The use of renewable energy sources instead of fossil fuel is a necessity for humanity. The Sun is a green and cheap source of energy: 10 minutes of solar irradiation onto the Earth's surface is equal to the total yearly human energy consumption $[1,2]$. The world energy challenge can be won harnessing the Sun power with photovoltaic technologies. Organic photovoltaic devices (OPVs) based on conjugated polymers and oligomers have received a lot of attention because of their potential for lightweight, flexible, and low cost photovoltaic energy conversion [3-7]. Among them, the most common devices are bulk-heterojunction (BHJ) polymer solar cells made upon blending an electron donor conjugated polymer with an electron acceptor material such as fullerene derivatives [3-7]. Fullerene-based OPV can be fabricated via vapor deposition; however, considering the expected demand for enhancing cost performance by mass production in the near future, application of roll-to-roll processing (i.e., the solvent casting method) appears highly desirable [8]. Therefore, development of stable fullerene derivatives that show both high power conversion efficiency and sufficient solubility in organic solvents is strongly desired [3-7]. Various types of fullerene derivatives for use as OPV acceptor materials have thus been developed. [6,6]-Phenyl-C61-butyric acid methyl ester (PCBM) $[9,10]$ is known to be the best blending material among these derivatives as an acceptor with polythiophenes such as regioregular poly(3-hexylthiophene) (P3HT), which is a typical donor partner in polymer solar cells [3-7].

Although PCBM is the most popular acceptor material so far for BHJ polymer solar cells, it is important to explore new easily accessible C60 derivatives as acceptor partners for polymer donor materials with a huge diversity of chemical structures. Many efforts have been devoted to the modification of the PCBM skeleton by introducing substituents on the phenyl ring, exchanging methyl groups with long alkyl chains, an ethyleneoxy moiety, or a perfluoroalkyl chain to tune the miscibility, thermal properties, and energy levels, and the resulting methanofullerene derivatives have been used to control the film morphology, raise the open circuit voltage $\left(V_{\text {oc }}\right)$, and improve the device stability [11-17]. A few years ago, a PCBM analogue containing a thiophene moiety, 


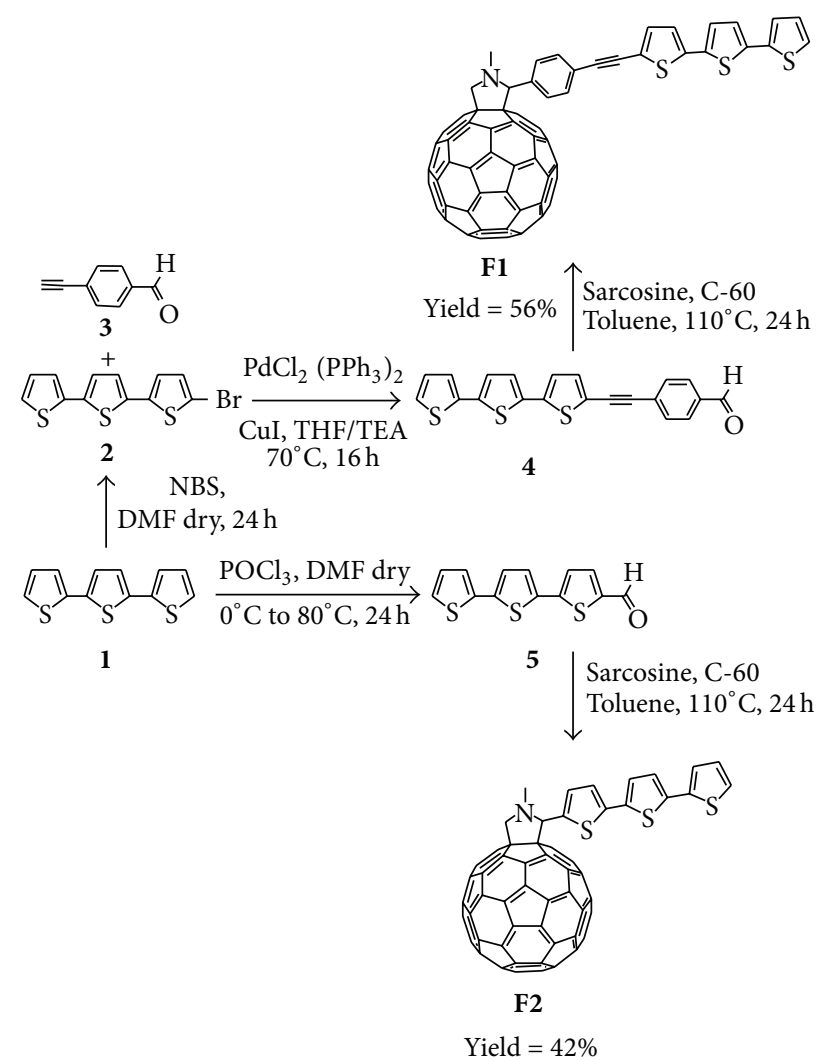

SCHEme 1: Synthesis of $\mathbf{F} \mathbf{1}$ and $\mathbf{F} 2$.

$[6,6]$-thienyl-C61-butyric acid methyl ester (TCBM), has been reported to exhibit device performance close to PCBM with $\mathrm{P} 3 \mathrm{HT}$ as the donor [11-17]. A series of TCBM analogues with different alkyl chains (methyl, hexyl, and ethylhexyl) at the 5 positions of the thiophene ring was then prepared [18]. Like methanofullerenes, fulleropyrrolidines are efficient acceptors for OPV devices and, recently, it was established that the introduction of a thiophene moiety on the pyrrolidine ring has a favorable effect on the power conversion energy (PCE) of a solar cell [19]. It was reported that 1-(2-(2-methoxyethoxy)ethyl)-2-(2-thiophen2 -yl)fulleropyrrolidine and related derivatives with bithiophene or terthiophene are efficient acceptor partners with $\mathrm{P} 3 \mathrm{HT}$, the compound bearing terthiophene being characterized by the highest $V_{\text {oc }}$ but lower fill factor (FF) and short circuit current $\left(J_{\mathrm{sc}}\right)$ due to reduced solubility when compared to the mono- and bithiophene derivatives [19]. In fact the solubility of a fullerene derivative strongly affects the morphology of its composite with $\mathrm{P} 3 \mathrm{HT}$ and therefore the efficiency of the cell $[20,21]$. These interesting results prompted us to design novel soluble terthiophene-substituted fullerene derivatives as easily accessible acceptor molecules for $\mathrm{BHJ}$ polymer solar cells (Scheme 1). We prepared both terthiophene-substituted fulleropyrrolidines (F1-F3) and methanofullerenes (F4-F5), with the aim of obtaining soluble acceptor materials with a good affinity for donor polymers based on thiophene units (Figure 1). As our work was in progress, as expected, it was reported by Saravanan et al. that F2 is a better electron

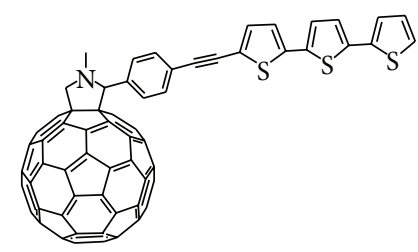

F1

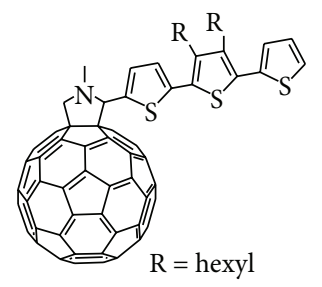

F3

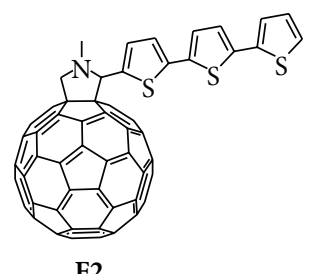

F2

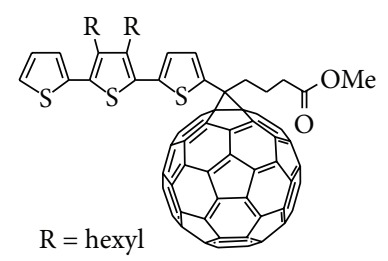

F4

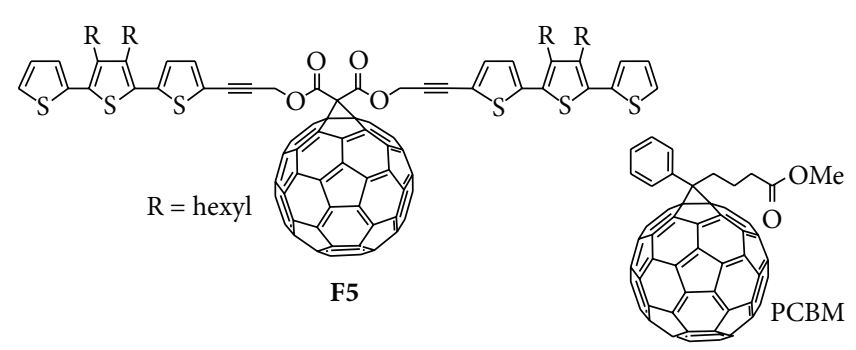

FIGURE 1: Terthiophene-substituted fullerene derivatives studied in the present work.

acceptor than PCBM for the fabrication of P3HT based bulkheterojunction solar cells [22].

\section{Materials and Methods}

General Comments. Solvents were dried by standard procedures: tetrahydrofuran (THF) and toluene were freshly distilled from $\mathrm{Na} /$ benzophenone under nitrogen atmosphere; $N, N$-dimethylformamide (DMF) was dried over activated molecular sieves; triethylamine $\left(\mathrm{Et}_{3} \mathrm{~N}\right)$ was freshly distilled over $\mathrm{KOH}$. All reagents were purchased from Sigma-Aldrich and were used without further purification $\left(2,2^{\prime}: 5^{\prime}, 2^{\prime \prime}\right.$ terthiophene $99 \%$ purity, fullerene- $\mathrm{C}_{60} 99.5 \%$ purity, and 4-[(trimethylsilyl)ethynyl] benzaldehyde $97 \%$ purity). Reactions requiring anhydrous conditions were performed under nitrogen. ${ }^{1} \mathrm{H}$ and ${ }^{13} \mathrm{C}$ NMR spectra were recorded at $400 \mathrm{MHz}$ on a Bruker AVANCE-400 instrument. Chemical shifts $(\delta)$ for ${ }^{1} \mathrm{H}$ and ${ }^{13} \mathrm{C}$ spectra are expressed in ppm relative to internal $\mathrm{Me}_{4} \mathrm{Si}$ as standard. Signals were abbreviated as follows: $s$ : singlet; bs: broad singlet; $d$ : doublet; $t$ : triplet; $q$ : quartet; $m$ : multiplet. Mass spectra were obtained by FT-ICR Mass Spectrometer APEX II \& Xmass software (Bruker Daltonics) and 4.7 Magnet and Autospec Fission Spectrometer (FAB ionization). MALDI-TOF mass spectra were obtained using a MICROFLEX LT (Bruker) with dithranol (DHB) or trans-2-[3-(4-tert-Butylphenyl)-2-methyl-2propenylidene]malononitrile (DCTB) as matrix. Absorption spectra were recorded at room temperature with a Perkin-Elmer Lambda 950 spectrophotometer. Samples were 
prepared by dissolving the compounds in chlorobenzene solutions in cell with $10 \mathrm{~mm}$ optical path length. Thin layer chromatography (TLC) was carried out with precoated Merck $\mathrm{F}_{254}$ silica gel plates whereas flash chromatography (FC) was carried out with Macherey-Nagel silica gel 60 (230-400 mesh).

\subsection{Preparation of Fullerene Derivatives F1-F3. Fullerenes} F1 and F2 were prepared according to Scheme 1, by using compounds 1-5 as intermediates, whereas $\mathbf{F} \mathbf{3}$ was prepared according to Scheme 2 with compounds $\mathbf{6}$ and $\mathbf{7}$ as intermediates.

2.2. Synthesis of Compound 2. Compound $\mathbf{2}$ was prepared as reported in the literature [23]. Under a nitrogen atmosphere, $\mathrm{N}$-bromosuccinimide (NBS) (176.3 mg, $0.99 \mathrm{mmol}, 1$ equiv.) was added in small portions to a solution of commercial $2,2^{\prime}: 5^{\prime}, 2^{\prime \prime}$-terthiophene (1) $(245.7 \mathrm{mg}, 0.99 \mathrm{mmol}, 1$ equiv.) in $\mathrm{N}, \mathrm{N}$-dimethylformamide $(14.1 \mathrm{~mL})$ and stirred for $24 \mathrm{~h}$ at room temperature. The reaction mixture was diluted with $\mathrm{CH}_{2} \mathrm{Cl}_{2}(15 \mathrm{~mL})$ and washed with water $(2 \times 50 \mathrm{~mL})$ : the organic layer was dried over $\mathrm{Na}_{2} \mathrm{SO}_{4}$ and evaporated to dryness. The product, isolated in quantitative yield $(324 \mathrm{mg})$, was used without further purification. ${ }^{1} \mathrm{H}-\mathrm{NMR}(400 \mathrm{MHz}$, $\left.\mathrm{CDCl}_{3}\right): \delta 7.25(\mathrm{td}, 1 \mathrm{H}, J=1.2 \mathrm{~Hz}, J=3.6 \mathrm{~Hz}), 7.20-7.19(\mathrm{~m}$, $1 \mathrm{H}), 7.10-7.08(\mathrm{~m}, 1 \mathrm{H}), 7.06-7.02(\mathrm{~m}, 2 \mathrm{H}), 6.99(\mathrm{~d}, 1 \mathrm{H}, J=$ $4 \mathrm{~Hz}), 6.93(\mathrm{~d}, 1 \mathrm{H}, J=3.6 \mathrm{~Hz})$.

2.3. Synthesis of Compound 4. The novel terthiophene derivative 4 was prepared following a procedure reported for related compounds [24]. To a solution of 4-ethynylbenzaldehyde (3) (42.2 mg, $0.32 \mathrm{mmol}, 1.2$ equiv.), obtained starting from 4-[(trimethylsilyl)ethynyl]benzaldehyde [25], and terthiophene derivative (2) (88.5 mg, $0.27 \mathrm{mmol}, 1$ equiv.) in degassed tetrahydrofuran $(6 \mathrm{~mL}),\left[\mathrm{PdCl}_{2}\left(\mathrm{PPh}_{3}\right)_{2}\right](7.6 \mathrm{mg}$, $4 \mathrm{~mol} \%), \mathrm{CuI}(3.1 \mathrm{mg}, 6 \mathrm{~mol} \%)$, and triethylamine $(1.5 \mathrm{~mL})$ were added, under a flow of nitrogen. The reaction mixture was left under stirring at $70^{\circ} \mathrm{C}$ overnight. The solvent was removed under reduced pressure and the residue was purified by flash chromatography, using dichloromethane/hexane $6 / 4$ as eluant, to give 4 as a dark yellow solid (66.1 mg; yield 65\%).

${ }^{1} \mathrm{H}-\mathrm{NMR}\left(400 \mathrm{MHz}, \mathrm{CDCl}_{3}\right): \quad \delta 10(\mathrm{~s}, 1 \mathrm{H}), 7.89(\mathrm{~d}, 2 \mathrm{H}$, $J=8.4 \mathrm{~Hz}), 7.67(\mathrm{~d}, 2 \mathrm{H}, J=8.4 \mathrm{~Hz}), 7.27(\mathrm{~d}, 2 \mathrm{H}, J=3.6 \mathrm{~Hz})$, $7.22(\mathrm{~d}, 1 \mathrm{H}, J=3.2 \mathrm{~Hz}), 7.14(\mathrm{~d}, 1 \mathrm{H}, J=3.6 \mathrm{~Hz}), 7.11(\mathrm{t}, 2 \mathrm{H}$, $J=3.6 \mathrm{~Hz}), 7.06(\mathrm{dd}, 1 \mathrm{H}, J=3.6 \mathrm{~Hz}, J=5.2 \mathrm{~Hz})$.

2.4. Synthesis of Compound 5. The known terthiophene derivative 5 [19] was prepared following a procedure reported for related compounds [26]. To a solution of $2,2^{\prime}: 5^{\prime}, 2^{\prime \prime}$ terthiophene (1) $(100.7 \mathrm{mg}, 0.40 \mathrm{mmol}, 1$ equiv.) in $N, N$ dimethylformamide $(3 \mathrm{~mL})$, under nitrogen and cooled to $0^{\circ} \mathrm{C}$, was added, in small portions, phosphoryl trichloride (75.1 mg, $0.49 \mathrm{mmol}, 1.2$ equiv.). The cool bath was then removed and the mixture was stirred for $24 \mathrm{~h}$ at $80^{\circ} \mathrm{C}$. After cooling to room temperature, the reaction mixture was neutralized with $\mathrm{NaOH}(2 \mathrm{~mL}, 1.25 \mathrm{M})$ and then diluted with $\mathrm{CH}_{2} \mathrm{Cl}_{2}$ and washed with water: the organic layer was dried

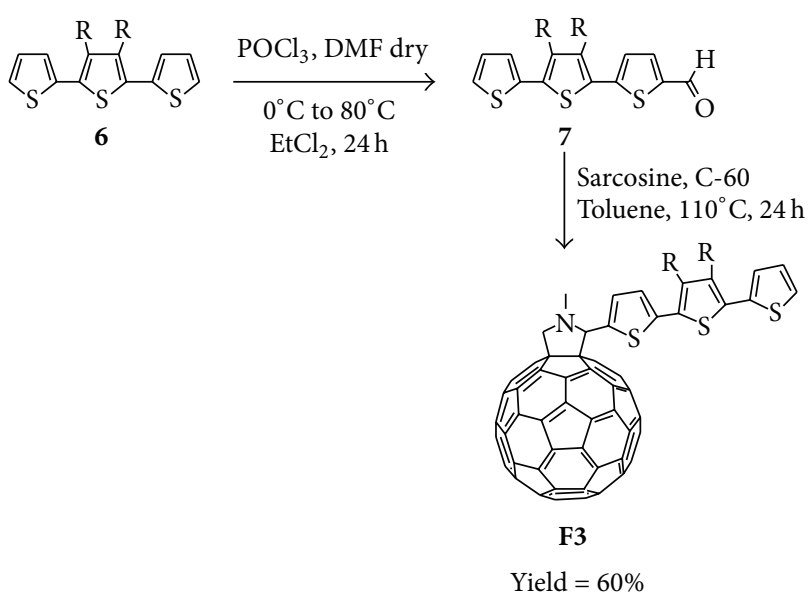

SCHEMe 2: Synthesis of F3.

over $\mathrm{Na}_{2} \mathrm{SO}_{4}$ and concentrated. The crude product was purified by flash chromatography, using dichloromethane as eluant, to give 5 as a dark solid (77.4 mg; yield $70 \%) .{ }^{1} \mathrm{H}-\mathrm{NMR}$ $\left(400 \mathrm{MHz}, \mathrm{CDCl}_{3}\right): \delta 9.88(\mathrm{~s}, 1 \mathrm{H}), 7.69(\mathrm{~d}, 1 \mathrm{H}, J=3.6 \mathrm{~Hz}), 7.30$ $(\mathrm{t}, 2 \mathrm{H}, J=4 \mathrm{~Hz}, J=2 \mathrm{~Hz}), 7.25(\mathrm{t}, 2 \mathrm{H}, J=4 \mathrm{~Hz}, J=3.2 \mathrm{~Hz})$, $7.15(\mathrm{~d}, 1 \mathrm{H}, J=4 \mathrm{~Hz}), 7.07(\mathrm{dd}, 1 \mathrm{H}, J=3.6 \mathrm{~Hz}, J=5.2 \mathrm{~Hz})$.

2.5. Synthesis of Compound $\mathbf{6}$. The terthiophene derivative $\mathbf{6}$ was prepared according to the literature [27]. To a solution of 2,5-dibromo-3,4-dihexylthiophene $(523.4 \mathrm{mg}, 1.27 \mathrm{mmol}, 1$ equiv.) and 2-tributylstannylthiophene (1.18 g, $3.17 \mathrm{mmol}, 2.5$ equiv.) in degassed tetrahydrofuran $(8.5 \mathrm{~mL})$, under a flow of nitrogen, $\left[\mathrm{PdCl}_{2}\left(\mathrm{PPh}_{3}\right)_{2}\right](71 \mathrm{mg}, 8 \mathrm{~mol} \%)$ and $\mathrm{KF}(581 \mathrm{mg}$, $10 \mathrm{mmol}, 7.9$ equiv.) were added. The reaction mixture was left under stirring at $70^{\circ} \mathrm{C}$ overnight. The solvent was removed under reduced pressure and the residue was diluted with $\mathrm{CH}_{2} \mathrm{Cl}_{2}$ and washed with water: the organic layer was dried over $\mathrm{Na}_{2} \mathrm{SO}_{4}$ and concentrated. The crude product was purified by flash chromatography, using hexane as eluant, to give 6 as a dark green oil ( $370 \mathrm{mg}$; yield 70\%). ${ }^{1} \mathrm{H}$-NMR data are fully consistent with data reported in the literature [27].

2.6. Synthesis of Compound 7. The terthiophene derivative 7 was prepared following a procedure reported for related compounds [26]. To a solution of $3^{\prime}, 4^{\prime}$-dihexyl-2,2':5',2' terthiophene (6) (257 mg, $0.62 \mathrm{mmol}, 1$ equiv.) and $N, N$ dimethylformamide $(49.7 \mathrm{mg}, 0.68 \mathrm{mmol}, 1.1$ equiv.) in dichloroethane $(6.2 \mathrm{~mL})$, under nitrogen and cooled to $0^{\circ} \mathrm{C}$, was added, in small portions, phosphoryl trichloride (104.3 $\mathrm{mg}, 0.68 \mathrm{mmol}, 1.1$ equiv.). The cool bath was then removed and the mixture was stirred overnight at $80^{\circ} \mathrm{C}$. After cooling to room temperature, the organic solvent was removed and the residue was dissolved in chloroform. A solution of $\mathrm{NaOH} 1.25 \mathrm{M}$ was added and stirred for $2 \mathrm{~h}$. The organic layer was washed with water, dried over $\mathrm{Na}_{2} \mathrm{SO}_{4}$, and concentrated. The crude product was purified by flash chromatography, using chloroform as eluant, to give pure 7 (207 mg; yield 75\%). ${ }^{1} \mathrm{H}-\mathrm{NMR}\left(400 \mathrm{MHz}, \mathrm{CDCl}_{3}\right): \quad \delta 9.91$ 
$(\mathrm{s}, 1 \mathrm{H}), 7.72(\mathrm{~d}, 1 \mathrm{H}, J=4 \mathrm{~Hz}), 7.38(\mathrm{dd}, 1 \mathrm{H}, J=1.2 \mathrm{~Hz}$, $J=5.2 \mathrm{~Hz}), 7.24(\mathrm{~d}, 1 \mathrm{H}, J=4 \mathrm{~Hz}), 7.19(\mathrm{dd}, 1 \mathrm{H}, J=0.8 \mathrm{~Hz}$, $J=3.6 \mathrm{~Hz}), 7.10(\mathrm{dd}, 1 \mathrm{H}, J=3.6 \mathrm{~Hz}, J=1.6 \mathrm{~Hz}), 2.82(\mathrm{bt}$, $2 \mathrm{H}, J=8 \mathrm{~Hz}, J=8.4 \mathrm{~Hz}), 2.74(\mathrm{bt}, 2 \mathrm{H}, J=8 \mathrm{~Hz}, J=8.4 \mathrm{~Hz}$ ), $1.63-1.53(\mathrm{~m}, 4 \mathrm{H}), 1.48-1.39(\mathrm{~m}, 4 \mathrm{H}), 1.36-1.33(\mathrm{~m}, 8 \mathrm{H}), 0.91$ (bd, $6 \mathrm{H})$. MS $\left(\mathrm{FAB}^{+}\right): m / z 376$.

2.7. Synthesis of the New Fulleropyrrolidines F1-F3. Fulleropyrrolidines F1-F3 were prepared by using the Prato cycloaddition procedure $[28,29]$. A mixture of the suitable aldehyde (1 equiv.), fullerene C-60 (1 equiv.), and sarcosine (8 equiv.) was refluxed for $24 \mathrm{~h}$ in anhydrous toluene under a nitrogen atmosphere. After cooling to room temperature, the solvent was evaporated under vacuum and the residue was purified by flash chromatography, as indicated in each case.

2.8. Synthesis of $\boldsymbol{F}$. The crude product was purified by flash chromatography, using hexane/toluene from $4 / 6$ to $3 / 7$ as eluant. Yield is $56 \% .{ }^{1} \mathrm{H}-\mathrm{NMR}\left(400 \mathrm{MHz}, \mathrm{CDCl}_{3}\right): \delta 7.98$ (bs, $2 \mathrm{H}), 7.63(\mathrm{~d}, 2 \mathrm{H}, J=8 \mathrm{~Hz}), 7.25(\mathrm{bd}, 1 \mathrm{H}, J=4 \mathrm{~Hz}), 7.20-7.17(\mathrm{~m}$, $2 \mathrm{H}), 7.10(\mathrm{q}, 2 \mathrm{H}, J=4 \mathrm{~Hz}, J=7.2 \mathrm{~Hz}), 7.06(\mathrm{~d}, 1 \mathrm{H}, J=4 \mathrm{~Hz})$, $7.04(\mathrm{dd}, 1 \mathrm{H}, J=4.8 \mathrm{~Hz}, J=3.6 \mathrm{~Hz}), 5.31(\mathrm{~s}, 1 \mathrm{H}), 5.26$ (bs, $1 \mathrm{H}), 4.46(\mathrm{~d}, 1 \mathrm{H}, J=10 \mathrm{~Hz}), 3.02(\mathrm{~s}, 3 \mathrm{H})$. MALDI-TOF MS: $m / z 1122.9\left(\mathrm{C}_{83} \mathrm{H}_{17} \mathrm{NS}_{3}\right.$ requires 1123.1, matrix DCTB).

2.9. Synthesis of $\mathbf{F} 2$. The crude product was purified by flash chromatography, using hexane/toluene from $1 / 1$ to $3 / 7$ as eluant. Yield is $42 \% .{ }^{1} \mathrm{H}-\mathrm{NMR}\left(400 \mathrm{MHz}, \mathrm{CDCl}_{3}+\mathrm{CS}_{2}\right): \delta$ $7.38(\mathrm{bs}, 1 \mathrm{H}), 7.23(\mathrm{~d}, 1 \mathrm{H}, J=5.2 \mathrm{~Hz}), 7.17(\mathrm{~d}, 1 \mathrm{H}, J=3.6 \mathrm{~Hz})$, $7.13(\mathrm{~d}, 1 \mathrm{H}, J=3.6 \mathrm{~Hz}), 7.11(\mathrm{~d}, 1 \mathrm{H}, J=4 \mathrm{~Hz}), 7.08(\mathrm{~d}, 1 \mathrm{H}$, $J=3.6 \mathrm{~Hz}), 7.03(\mathrm{dd}, 1 \mathrm{H}, J=3.6 \mathrm{~Hz}, J=4.8 \mathrm{~Hz}), 5.29(\mathrm{~s}, 1 \mathrm{H})$, $5.05(\mathrm{~d}, 1 \mathrm{H}, J=9.6 \mathrm{~Hz}), 4.31(\mathrm{~d}, 1 \mathrm{H}, J=9.6 \mathrm{~Hz}), 2.99(\mathrm{~s}$, $3 \mathrm{H})$. MALDI-TOF MS: $m / z 1022.8\left(\mathrm{C}_{75} \mathrm{H}_{13} \mathrm{NS}_{3}\right.$ requires 1023 , without matrix).

2.10. Synthesis of F3. The crude product was purified by flash chromatography, using hexane/toluene $1 / 1$ as eluant. Yield is $60 \% .{ }^{1} \mathrm{H}-\mathrm{NMR}\left(400 \mathrm{MHz}, \mathrm{CDCl}_{3}\right): \delta 7.37(\mathrm{~d}, 1 \mathrm{H}, J=3.6 \mathrm{~Hz})$, $7.32(\mathrm{bd}, 1 \mathrm{H}, J=5.2 \mathrm{~Hz}), 7.20-7.18(\mathrm{~m}, 1 \mathrm{H}), 7.14-7.13(\mathrm{~m}, 1 \mathrm{H})$, 7.08-7.06 (m, 1H), $5.28(\mathrm{~s}, 1 \mathrm{H}), 5.02(\mathrm{~d}, 1 \mathrm{H}, J=9.6 \mathrm{~Hz}), 4.28$ $(\mathrm{d}, 1 \mathrm{H}, J=9.6 \mathrm{~Hz}), 2.97(\mathrm{~s}, 3 \mathrm{H}), 2.72-2.64(\mathrm{~m}, 4 \mathrm{H}), 1.48-$ $1.44(\mathrm{~m}, 2 \mathrm{H}), 1.40-1.37$ (m, 2H), $1.32-1.27$ (m, 12H), 0.91-0.85 (m, 6H). MALDI-TOF MS: $m / z 1192.6\left(\mathrm{C}_{87} \mathrm{H}_{37} \mathrm{NS}_{3}\right.$ requires 1191.2, matrix DHB).

2.11. Preparation of Fullerene F4. Fullerene F4 was prepared from compounds $\mathbf{8 - 1 0}$ as shown in Scheme 3.

2.12. Synthesis of Compound 9. The novel compound 9 was prepared as follows. To a solution of $3^{\prime}, 4^{\prime}$ - dihexyl-2,2 $2^{\prime}: 5^{\prime}, 2^{\prime \prime}$ terthiophene (6) (409.6 mg, $0.98 \mathrm{mmol}, 1$ equiv.) and methyl 5-chloro-5-oxopentanoate (8) (161.7 mg, $0.98 \mathrm{mmol}, 1$ equiv.) in toluene $(1.6 \mathrm{~mL})$, under nitrogen and cooled to $0^{\circ} \mathrm{C}$, was added, in small portions, tin tetrachloride $(255.3 \mathrm{mg}$, $0.98 \mathrm{mmol}, 1$ equiv.) and stirred for $2 \mathrm{~h}$. The reaction mixture was diluted with $\mathrm{CH}_{2} \mathrm{Cl}_{2}$ and washed with water: the organic layer was dried over $\mathrm{Na}_{2} \mathrm{SO}_{4}$ and concentrated. The crude product obtained was purified by flash chromatography, using dichloromethane as eluant, to give $\mathbf{9}$ as a pure product (347 mg; yield 65\%). ${ }^{1} \mathrm{H}-\mathrm{NMR}\left(400 \mathrm{MHz}, \mathrm{CDCl}_{3}\right.$ ): $\delta 7.67(\mathrm{~d}$, $1 \mathrm{H}, J=4 \mathrm{~Hz}), 7.36(\mathrm{dd}, 1 \mathrm{H}, J=0.8 \mathrm{~Hz}, J=5.2 \mathrm{~Hz}), 7.18-7.15$ $(\mathrm{m}, 2 \mathrm{H}), 7.09(\mathrm{dd}, 1 \mathrm{H}, J=3.6 \mathrm{~Hz}, J=5.2 \mathrm{~Hz}), 3.71(\mathrm{~s}, 3 \mathrm{H})$, 2.99 (t, $2 \mathrm{H}, J=7.2 \mathrm{~Hz}), 2.81(\mathrm{bt}, 2 \mathrm{H}), 2.71(\mathrm{bt}, 2 \mathrm{H}), 2.48(\mathrm{t}$, $2 \mathrm{H}, J=7.2 \mathrm{~Hz}), 2.15-2.08(\mathrm{~m}, 2 \mathrm{H}), 1.58-1.53(\mathrm{~m}, 2 \mathrm{H}), 1.47-$ $1.39(\mathrm{~m}, 4 \mathrm{H}), 1.36-1.29(\mathrm{~m}, 8 \mathrm{H}), 0.92(\mathrm{bd}, 6 \mathrm{H}, J=6.8 \mathrm{~Hz})$.

2.13. Synthesis of Compound 10. The novel compound $\mathbf{1 0}$ was prepared as follows. A mixture of $9(165 \mathrm{mg}, 0.3 \mathrm{mmol}, 1$ equiv.) and $p$-toluenesulfonyl hydrazide $(68 \mathrm{mg}, 0.36 \mathrm{mmol}$, 1.2 equiv.) was refluxed in $\mathrm{MeOH}(0.5 \mathrm{~mL})$ for $18 \mathrm{~h}$. After cooling to room temperature, the organic solvent was removed under reduced pressure and the residue was dissolved in dichloromethane and washed with water. The organic layer was dried over $\mathrm{Na}_{2} \mathrm{SO}_{4}$ and concentrated. The residue was purified by flash chromatography, using hexane/ethyl acetate $7: 3$ as eluant, to give 10 as a pure product (148 mg; yield $75 \%$ ). ${ }^{1} \mathrm{H}-\mathrm{NMR}\left(400 \mathrm{MHz}, \mathrm{CDCl}_{3}\right): \quad \delta 8.97(\mathrm{~s}, 1 \mathrm{H}), 7.94(\mathrm{~d}, 2 \mathrm{H}$, $J=8 \mathrm{~Hz}), 7.35-7.30(\mathrm{~m}, 2 \mathrm{H}), 7.16(\mathrm{~d}, 1 \mathrm{H}, J=1.2 \mathrm{~Hz}), 7.14(\mathrm{~d}$, $1 \mathrm{H}, J=4 \mathrm{~Hz}), 7.09(\mathrm{dd}, 1 \mathrm{H}, J=3.6 \mathrm{~Hz}, J=4.8 \mathrm{~Hz}), 7.01(\mathrm{~d}$, $1 \mathrm{H}, J=3.6 \mathrm{~Hz}), 3.82(\mathrm{~s}, 3 \mathrm{H}), 2.77-2.69(\mathrm{~m}, 4 \mathrm{H}), 2.62(\mathrm{t}, 2 \mathrm{H}$, $J=7.6 \mathrm{~Hz}, J=8 \mathrm{~Hz}), 2.45(\mathrm{~s}, 3 \mathrm{H}), 2.35(\mathrm{t}, 2 \mathrm{H}, J=5.2 \mathrm{~Hz}$, $J=6.4 \mathrm{~Hz}), 1.58-1.54(\mathrm{~m}, 4 \mathrm{H}), 1.45-1.42(\mathrm{~m}, 4 \mathrm{H}), 1.37-1.29(\mathrm{~m}$, $8 \mathrm{H}), 0.92(\mathrm{bd}, J=6.4 \mathrm{~Hz})$. MS $\left(\mathrm{FAB}^{+}\right): m / z 712$.

2.14. Synthesis of $\mathbf{F 4}$. The new methanofullerene F4 was prepared following procedures reported for related compounds $[18,30,31]$. A mixture of $10(55.3 \mathrm{mg}, 0.084 \mathrm{mmol}, 1.2$ equiv.), sodium methoxide ( $4.5 \mathrm{mg}, 0.084 \mathrm{mmol}, 1.2$ equiv.), and dry pyridine $(0.84 \mathrm{~mL})$ was stirred at room temperature for $30 \mathrm{~min}$. Then a solution of fullerene C-60 (50.3 mg, $0.07 \mathrm{mmol}, 1$ equiv.) in $o$-dichlorobenzene $(4.1 \mathrm{~mL})$ was added, and the homogeneous reaction mixture was stirred at $75^{\circ} \mathrm{C}$ under nitrogen overnight. Then the mixture was refluxed for $24 \mathrm{~h}\left(180^{\circ} \mathrm{C}\right)$; after cooling to room temperature the solvent was evaporated at reduced pressure, and the residue was purified by column chromatography on silica gel with toluene/hexane $6: 4$ as eluent to give $\mathbf{F 4}$ as a pure

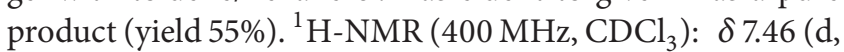
$1 \mathrm{H}, J=4 \mathrm{~Hz}$ ), $7.33(\mathrm{dd}, 1 \mathrm{H}, J=4.4 \mathrm{~Hz}, J=0.8 \mathrm{~Hz}), 7.18(\mathrm{dd}$, $1 \mathrm{H}, J=4.4 \mathrm{~Hz}, J=0.8 \mathrm{~Hz}), 7.15(\mathrm{~d}, 1 \mathrm{H}, J=4.4 \mathrm{~Hz}), 7.10$ $(\mathrm{dd}, 1 \mathrm{H}, J=3.6 \mathrm{~Hz}, J=5.2 \mathrm{~Hz}), 3.72(\mathrm{~s}, 3 \mathrm{H}), 3.01$ (bt, $2 \mathrm{H}$, $J=8 \mathrm{~Hz}$ ), 2.79 (bt, $2 \mathrm{H}, J=8.4 \mathrm{~Hz}, J=8 \mathrm{~Hz}), 2.73$ (bt, $2 \mathrm{H}$, $J=8.4 \mathrm{~Hz}, J=8 \mathrm{~Hz}), 2.63(\mathrm{t}, 2 \mathrm{H}, J=7.2 \mathrm{~Hz}), 1.63-1.56(\mathrm{~m}$, $4 \mathrm{H}), 1.45-1.40(\mathrm{~m}, 4 \mathrm{H}), 1.35-1.28(\mathrm{~m}, 8 \mathrm{H}), 0.91(\mathrm{bd}, 6 \mathrm{H}, J=$ $6.8 \mathrm{~Hz})$. MALDI-TOF MS: $m / z 1248.9\left(\mathrm{C}_{90} \mathrm{H}_{40} \mathrm{O}_{2} \mathrm{~S}_{3}\right.$ requires 1248.2, matrix DCTB).

2.15. Preparation of Fullerene F5. Fullerene F5 was prepared from compounds 11-13 as shown in Scheme 4.

2.16. Synthesis of Compound 11. Under a nitrogen atmosphere, $N$-bromosuccinimide (NBS) $(408.6 \mathrm{mg}, 0.98 \mathrm{mmol}$, 1 equiv.) was added in small portions to a solution of $3^{\prime}, 4^{\prime}$ dihexyl-2,2':5',2' -terthiophene (6) (147.7 mg, $0.98 \mathrm{mmol}, 1$ equiv.) in $\mathrm{N}, \mathrm{N}$-dimethylformamide $(14 \mathrm{~mL}, 0.07 \mathrm{M})$ and 


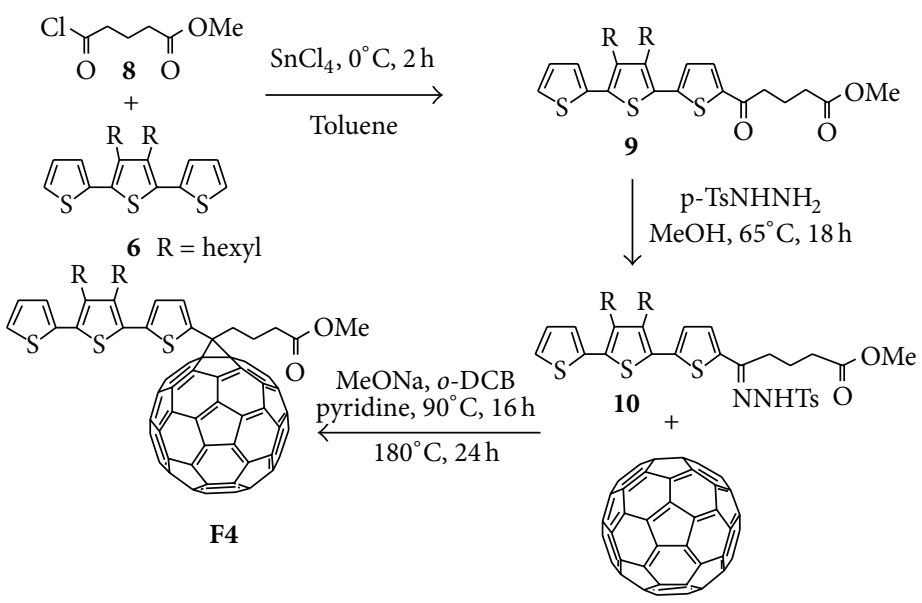

SCHeme 3: Synthesis of F4.
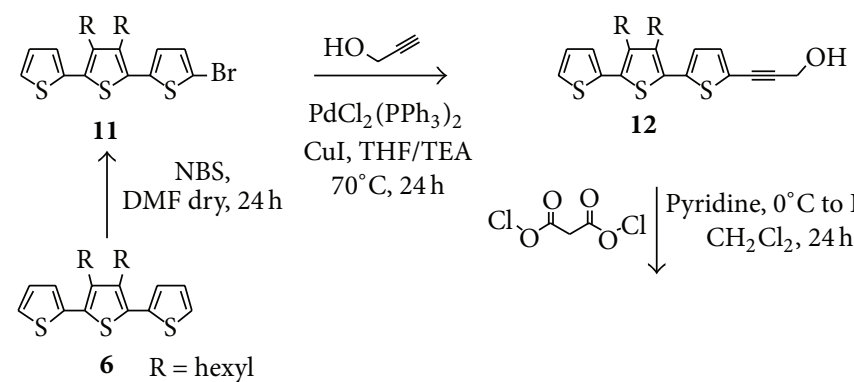

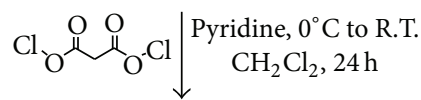

$6 \quad \mathrm{R}=$ hexyl

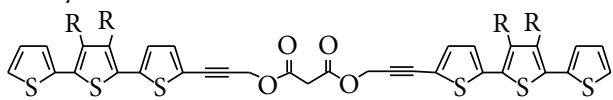

13

C-60, $\mathrm{I}_{2}, \mathrm{DBU}$,

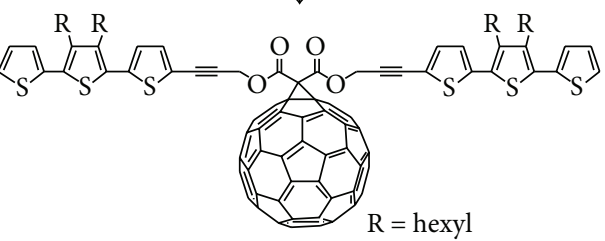

F5

Scheme 4: Synthesis of F5.

stirred for $24 \mathrm{~h}$ at room temperature. The reaction mixture was diluted with $\mathrm{CH}_{2} \mathrm{Cl}_{2}(15 \mathrm{~mL})$ and washed with water $(2 \times$ $50 \mathrm{~mL}$ ): the organic layer was dried over $\mathrm{Na}_{2} \mathrm{SO}_{4}$ and concentrated. The product, isolated in quantitative yield $(485 \mathrm{mg})$, was used without further purification. ${ }^{1} \mathrm{H}-\mathrm{NMR}(400 \mathrm{MHz}$, $\left.\mathrm{CDCl}_{3}\right): \quad \delta 7.40-7.32(\mathrm{~m}, 1 \mathrm{H}), 7.14(\mathrm{~d}, 1 \mathrm{H}, J=2.4 \mathrm{~Hz}), 7.08$ $(\mathrm{dd}, 1 \mathrm{H}, J=3.6 \mathrm{~Hz}, J=5.2 \mathrm{~Hz}), 7.04-7.01(\mathrm{~m}, 1 \mathrm{H}), 6.89-6.87$ (m, $1 \mathrm{H}), 2.75-2.64(\mathrm{~m}, 4 \mathrm{H}), 1.63-1.56(\mathrm{~m}, 4 \mathrm{H}), 1.44-1.40(\mathrm{~m}$, $4 \mathrm{H}), 1.34-1.28(\mathrm{~m}, 8 \mathrm{H}), 0.90(\mathrm{bd}, 6 \mathrm{H}, J=6.8 \mathrm{~Hz})$.

2.17. Synthesis of Compound 12. The new terthiophene derivative 12 was prepared according to the following procedure. To a solution of propargyl alchol (36.5 mg, $0.65 \mathrm{mmol}, 1.1$ equiv.) and 11 (247.8 mg, $0.59 \mathrm{mmol}, 1$ equiv.) in degassed tetrahydrofuran $(14.7 \mathrm{~mL})$, under a flow of nitrogen, were added $\left[\mathrm{PdCl}_{2}\left(\mathrm{PPh}_{3}\right)_{2}\right]$ (16.6 mg, $\left.4 \mathrm{~mol} \%\right)$, CuI (6.7 mg, $\left.6 \mathrm{~mol} \%\right)$, and triethylamine $(3.7 \mathrm{~mL})$. The reaction mixture was left under stirring at $70^{\circ} \mathrm{C}$ overnight. The solvent was removed under reduced pressure and the residue was purified by flash chromatography, using chloroform as eluant, to give $\mathbf{1 2}$ (152 mg; yield 55\%). ${ }^{1} \mathrm{H}-\mathrm{NMR}\left(400 \mathrm{MHz}, \mathrm{CDCl}_{3}\right): \delta 7.34(\mathrm{dd}$, $1 \mathrm{H}, J=4.8 \mathrm{~Hz}, J=0.8 \mathrm{~Hz}), 7.18(\mathrm{~d}, 1 \mathrm{H}, J=4.8 \mathrm{~Hz}), 7.15$ $(\mathrm{dd}, 1 \mathrm{H}, J=3.6 \mathrm{~Hz}, J=0.8 \mathrm{~Hz}), 7.09(\mathrm{dd}, 1 \mathrm{H}, J=3.6 \mathrm{~Hz}$, $J=5.2 \mathrm{~Hz}), 7.01(\mathrm{~d}, 1 \mathrm{H}, J=3.6 \mathrm{~Hz}), 4.55(\mathrm{~s}, 2 \mathrm{H}), 2.74-2.68$ (m, $4 \mathrm{H}), 1.59-1.55(\mathrm{~m}, 4 \mathrm{H}), 1.44-1.41(\mathrm{~m}, 4 \mathrm{H}), 1.36-1.29(\mathrm{~m}$, $8 \mathrm{H}), 0.92(\mathrm{bd}, 6 \mathrm{H}, J=6.8 \mathrm{~Hz}$ ). 
2.18. Synthesis of Compound 13. The new terthiophene derivative 13 was prepared as follows. Malonyl dichloride $(1.75 \mathrm{~mL}$, $18 \mathrm{mmol}, 1$ equiv.) was added to a solution of terthiophene 12 (142 mg, $0.3 \mathrm{mmol}, 2$ equiv.) and pyridine $(23.7 \mathrm{mg}, 0.3 \mathrm{mmol}$, 2 equiv.) in dichloromethane $(2.1 \mathrm{~mL})$ at $0^{\circ} \mathrm{C}$ under nitrogen. After $1 \mathrm{~h}$, the mixture was allowed to warm up to room temperature and then stirred for $18 \mathrm{~h}$, filtered, and evaporated. The residue was purified by flash chromatography, using dichloromethane/hexane $8 / 2$ as eluant, to give 13 (106 mg; yield 70\%). ${ }^{1} \mathrm{H}$-NMR $\left(400 \mathrm{MHz}, \mathrm{CDCl}_{3}\right): \delta 7.34(\mathrm{~d}, 2 \mathrm{H}, J=$ $5.2 \mathrm{~Hz}), 7.21(\mathrm{~d}, 2 \mathrm{H}, J=4 \mathrm{~Hz}), 7.14(\mathrm{dd}, 2 \mathrm{H}, J=3.6 \mathrm{~Hz}$, $J=1.2 \mathrm{~Hz}), 7.08(\mathrm{dd}, 2 \mathrm{H}, J=3.6 \mathrm{~Hz}, J=5.2 \mathrm{~Hz}), 7.01(\mathrm{~d}, 2 \mathrm{H}$, $J=3.6 \mathrm{~Hz}), 5.05(\mathrm{~s}, 4 \mathrm{H}), 3.57(\mathrm{~s}, 2 \mathrm{H}), 2.73-2.67(\mathrm{~m}, 8 \mathrm{H}), 1.58-$ $1.54(\mathrm{~m}, 8 \mathrm{H}), 1.46-1.41(\mathrm{~m}, 8 \mathrm{H}), 1.35-1.29(\mathrm{~m}, 16 \mathrm{H}), 0.93(\mathrm{~m}$, $12 \mathrm{H})$. MS (FAB $\left.{ }^{+}\right): m / z 1008$.

2.19. Synthesis of F5. The new methanofullerene F5 was prepared following procedures reported for similar compounds [32, 33]. 1,8-diazabicyclo[5.4.0] undec-7-ene (19.3 mg, $0.125 \mathrm{mmol}, 2.5$ equiv.) was added under nitrogen at room temperature to a stirred solution of fullerene C-60 (39 mg, $0.05 \mathrm{mmol}, 1$ equiv.), $\mathrm{I}_{2}$ (19 mg, $0.075 \mathrm{mmol}, 1.5$ equiv.), and 13 (55 mg, $0.05 \mathrm{mmol}, 1$ equiv.) in toluene $(39 \mathrm{~mL})$ at room temperature. The resulting solution was stirred for $12 \mathrm{~h}$ and then filtered through a short plug of silica $\left(\mathrm{CH}_{2} \mathrm{Cl}_{2}\right)$ and evaporated. The residue was purified by flash chromatography, using hexane/toluene 6/4 as eluant, to give $\mathbf{F 5}$ (yield 52\%). ${ }^{1} \mathrm{H}-\mathrm{NMR}\left(400 \mathrm{MHz}, \mathrm{CDCl}_{3}\right): \delta 7.33(\mathrm{dd}, 2 \mathrm{H}, J=5.2 \mathrm{~Hz}$, $J=1.2 \mathrm{~Hz}), 7.20(\mathrm{~d}, 2 \mathrm{H}, J=4 \mathrm{~Hz}), 7.13(\mathrm{dd}, 2 \mathrm{H}, J=3.6 \mathrm{~Hz}$, $J=1.2 \mathrm{~Hz}), 7.07(\mathrm{dd}, 2 \mathrm{H}, J=3.6 \mathrm{~Hz}, J=4.8 \mathrm{~Hz}), 6.98(\mathrm{~d}, 2 \mathrm{H}$, $J=4 \mathrm{~Hz}), 5.38(\mathrm{~s}, 4 \mathrm{H}), 2.73-2.68(\mathrm{~m}, 8 \mathrm{H}), 1.56-1.54(\mathrm{~m}, 8 \mathrm{H})$, 1.43-1.38 (m, 8H), 1.34-1.28 (m, 16H), 0.92 (m, 12H). MALDITOF MS: $m / z 1729.3\left(\mathrm{C}_{117} \mathrm{H}_{66} \mathrm{O}_{4} \mathrm{~S}_{6}\right.$ requires 1727.3 , matrix DCTB).

2.20. Electrochemical Characterization. The cyclovoltammetric $(\mathrm{CV})$ characterization was carried out with an Autolab PGSTAT $128 \mathrm{~N}$ potentiostat, run by a PC with GPES software. The working cell included a Glassy Carbon (GC) disk embedded in Teflon (Amel, surface $0.071 \mathrm{~cm}^{2}$ ) as the working electrode, a Platinum counter electrode (Metrohm), and an aqueous saturated calomel electrode (SCE, Amel) as the reference electrode. The sample was dissolved in o-dichlorobenzene $(\approx 0.5 \mathrm{mg} / \mathrm{mL})$ and drop coated from a capillary on the GC electrode. The electrolytic solution was acetonitrile (Carlo Erba, HPLC grade) with $0.1 \mathrm{M}$ tetrabutylammonium tetrafluoroborate TBATFB (Fluka, electrochemical grade). The solution was degassed with argon purging. The scan rate was $200 \mathrm{mV} \mathrm{s}^{-1}$. According to IUPAC recommendations the data have been referred to the $\mathrm{Fc}^{+} / \mathrm{Fc}$ redox couple (ferrocenium/ferrocene).

$E_{\text {HOMO }}$ and $E_{\text {LUMO }}$ values were extrapolated from the onset peaks potential.

2.21. Preparation and Characterization of Solar Cells. Solar cells were fabricated on patterned ITO-coated glass substrates previously cleaned with detergent and water and then ultrasonicated in acetone and isopropyl alcohol for $15 \mathrm{~min}$ each.
A PEDOT : PSS (Clevios P VP AI 4083) layer was spin-coated at $3000 \mathrm{rpm}$ onto air plasma cleaner ITO-coated substrates to a thickness of around $40 \mathrm{~nm}$ and then baked in an oven at $120^{\circ} \mathrm{C}$ for $10 \mathrm{~min}$. Fullerenes and P3HT were dissolved separately in chlorobenzene $(20 \mathrm{mg} / \mathrm{mL}$ ) (Carlo Erba, HPLC grade), mixed 1:1 w/w obtaining a total concentration of $10 \mathrm{mg} / \mathrm{mL}$, and then stirred overnight at $70^{\circ} \mathrm{C}$. The blend solutions were spin-coated at 600 and $1200 \mathrm{rpm}$ in glove box onto the ITO/PEDOT: PSS substrates. The thickness of the active layers, measured with a Veeco Dektak 150 profilometer, ranged between $50 \mathrm{~nm}$ and $130 \mathrm{~nm}$. Then the samples were completed with the thermal evaporation of the $\mathrm{Al}(80 \mathrm{~nm})$ cathode at a base pressure of $10^{-6} \mathrm{mbar}$. The active device area was $25 \mathrm{~mm}^{2}$. The devices were postproduction thermal annealed in glove box (nitrogen filled) at $150^{\circ} \mathrm{C}$ for $10 \mathrm{~min}$. The device electrical characterization was carried out at room temperature in glove box. Solar cells were illuminated using a solar simulator (Sun 2000, Abet Technologies) and the light power intensity was calibrated at AM1.5 illumination conditions ( $\left.100 \mathrm{~mW} \mathrm{~cm}^{-2}\right)$ using a certified silicon solar cell. The current-voltage curves were taken with a Keithley 2602 source measure.

\section{Results and Discussion}

Terthiophene is an interesting $\pi$-conjugated electronreleasing substituent group that can influence both the light absorbing behavior and charge separation process of fullerenes. Interestingly, it was reported that 1-(2-(2-methoxyethoxy)ethyl)-2-(terthiophene)fulleropyrrolidine is an efficient acceptor partner with P3HT, being characterized by a higher $V_{\text {oc }}$ but lower fill factor and shorter circuit current with respect to related compounds bearing thiophene or bithiophene instead of the terthiophene moiety, attributed to its lower solubility [19]. These interesting results prompted us to design novel soluble terthiophene-substituted fullerene derivatives as easily accessible acceptor molecules for BHJ polymer solar cells (Scheme 1). We prepared both terthiophene-substituted fulleropyrrolidines (F1-F3) and methanofullerenes (F4-F5), with the aim of obtaining soluble acceptor materials with a good affinity for donor polymers based on thiophene units.

The novel terthiophene-substituted fulleropyrrolidines (F1, F3) and the known F2 [22] were prepared following a method similar to that originally developed by Prato and Maggini and coworkers (Schemes 1 and 2) [28, 29]. Sarcosine was treated with [C60]-fullerene in the presence of a suitable terthiophene-substituted aldehyde, in toluene, and the mixture was heated under reflux for $24 \mathrm{~h}$ under a nitrogen atmosphere.

The novel terthiophene-substituted methanofullerene F4 was prepared following the procedure reported for other methanofullerenes $[18,30,31]$, by reaction of the $p$ tosylhydrazone $\mathbf{1 0}$ with sodium methoxide and fullerene C60 (Scheme 3), whereas F5 was synthesized by the Bingel reaction $[32,33]$ treating the novel bisterthiophenylmalonate 13 with iodine, fullerene, and 1,8-diazabicyclo[5.4.0] undec-7ene (Scheme 4). 


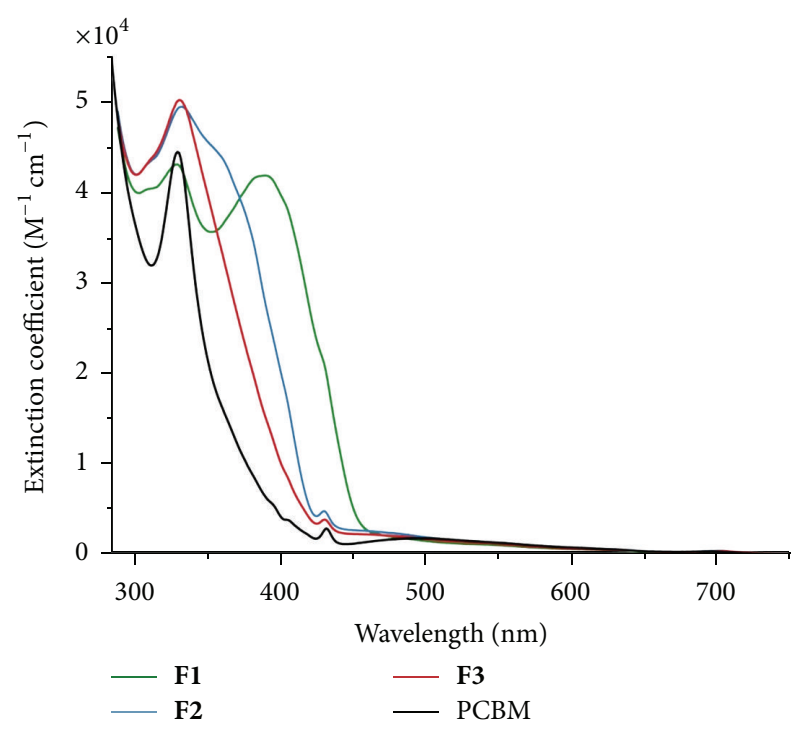

Figure 2: UV-visible absorption spectra of F1-F3 and PCBM in chlorobenzene.

All fulleropyrrolidines and methanofullerenes were purified by silica gel flash chromatography and characterized by elemental analyses, ${ }^{1} \mathrm{H}$ NMR and UV-visible spectroscopies, mass spectrometry, and cyclovoltammetry (see Section 2).

Figures 2 and 3 show the UV-visible absorption spectra of fullerenes F1-F5 along with that of PCBM in chlorobenzene solution.

The fulleropyrrolidine $\mathbf{F} 2$ shows a broad absorption band between 350 and $400 \mathrm{~nm}$, as expected for a terthiophene moiety [22]. This band is red shifted in compound $\mathbf{F} \mathbf{1}$, in agreement with the presence of a $\pi$-delocalized bridge between the pyrrolidine and the terthiophene moiety, and blue shifted in compound F3, due to the presence of the hexyl chains, responsible of the tilting of the structure and the final reduced conjugation.

Red shifting is observed in the compounds F4 and F5 in comparison with PCBM. Interestingly also a large enhancement in the $\varepsilon$ of the peak at $330 \mathrm{~nm}$ (assigned to the fullerene) is obtained. Theoretically this enhancement can benefit the performance of the solar cells being the absorption in this region complementary to P3HT. In fact, it was reported that fullerenes' derivatives with a better light absorption can lead to a better power conversion efficiency since more photons are available to be converted into electricity [34].

The electrochemical properties of the various fullerenes were examined by cyclic voltammetry (CV). Current potential profiles are shown in Figures 4 and 5.

We use the first oxidation and reduction potentials to estimate the HOMO and LUMO energy levels by means of equations $E_{\mathrm{HOMO}}(\mathrm{eV})=-\left(E_{\mathrm{OX}}+4.8\right)$ and $E_{\mathrm{LUMO}}(\mathrm{eV})=-\left(E_{\mathrm{RED}}+\right.$ 4.8 , which involve the use of the internal ferrocene standard value of $-4.8 \mathrm{eV}$ with respect to the vacuum level $[35,36]$. The results are summarized in Table 1. Interestingly, all the novel fullerene derivatives have an enhanced LUMO level with respect to PCBM, possibly improving the $V_{\mathrm{oc}}$. In fact,

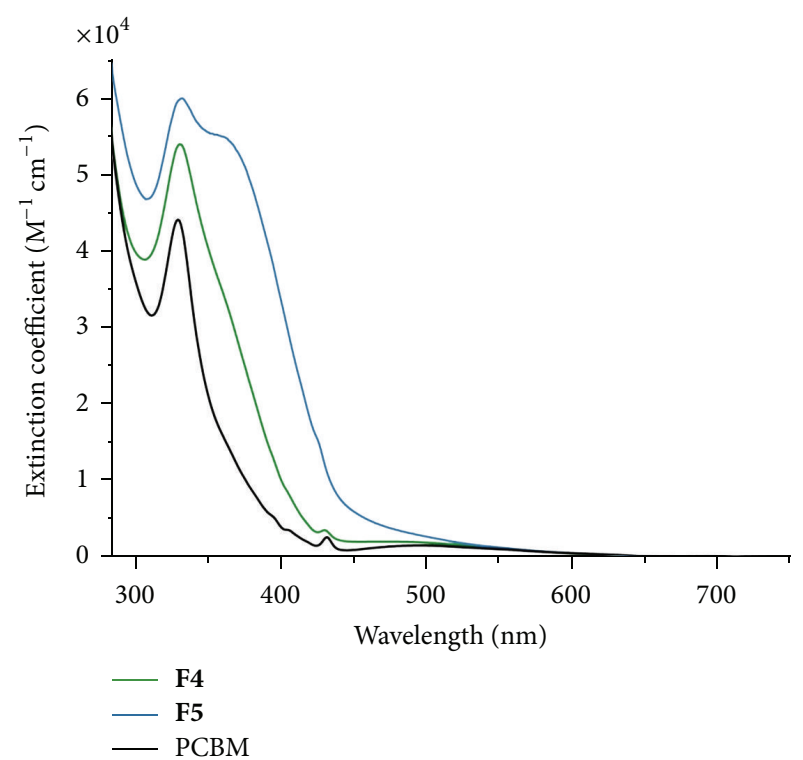

FIGURE 3: UV-visible absorption spectra of F4, F5, and PCBM in chlorobenzene.

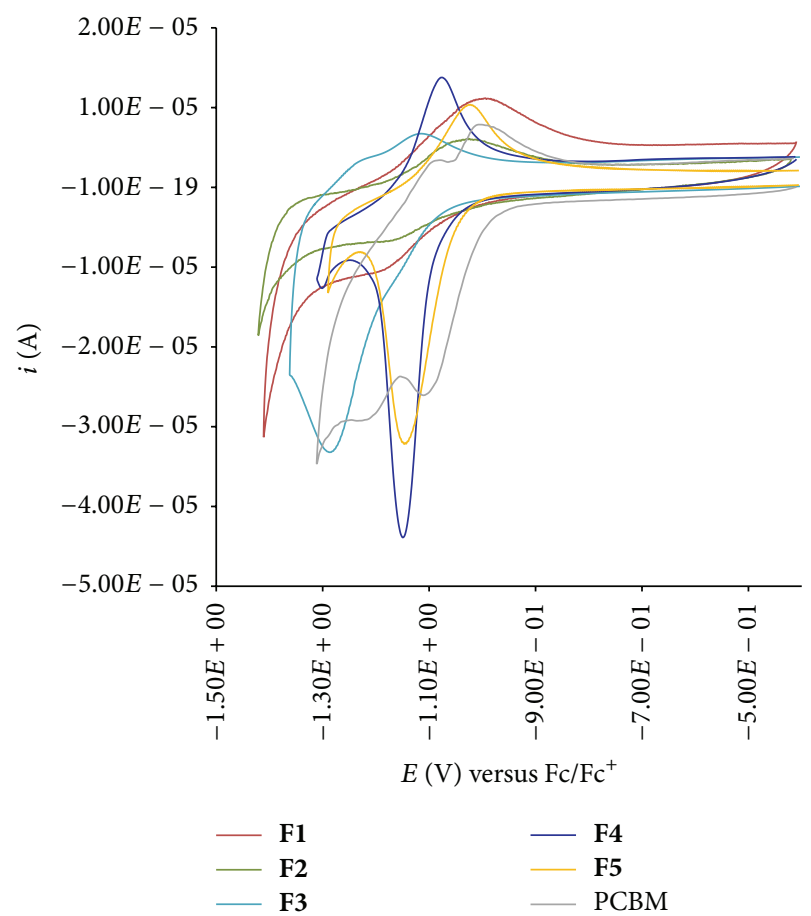

Figure 4: Synopsis of cathodic part of cyclovoltammograms for fullerenes F1-F5 and PCBM.

Kim and coworkers reported that the $V_{\mathrm{oc}}$ of an OPV device is determined by the difference between the HOMO level of the p-type semiconductor and the LUMO level of the n-type conductor [37]. Fullerenes F1-F3 and F5 are characterized by a remarkably low band gap due to a relatively high HOMO level. 


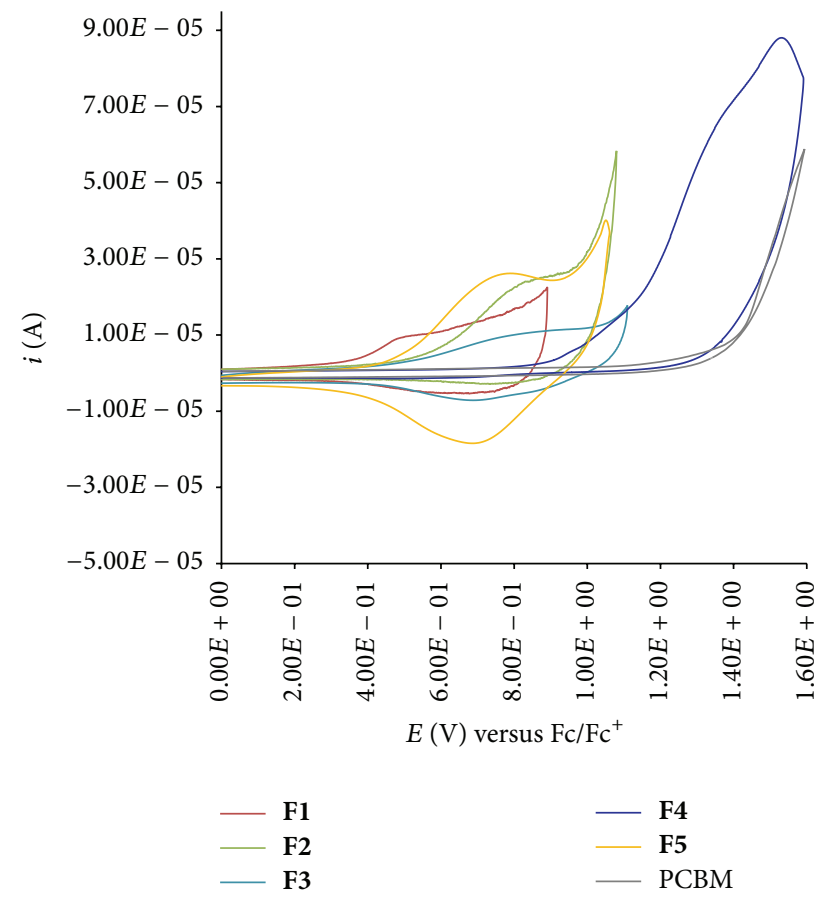

FIGURE 5: Synopsis of anodic part of cyclovoltammograms for fullerenes F1-F5 and PCBM.

TABLE 1

\begin{tabular}{lccc}
\hline Fullerene derivative & $E_{\text {HOMO }}(\mathrm{eV})$ & $E_{\text {LUMO }}(\mathrm{eV})$ & Band gap $(\mathrm{eV})$ \\
\hline F1 & -5.15 & -3.78 & 1.37 \\
F2 & -5.27 & -3.78 & 1.49 \\
F3 & -5.29 & -3.74 & 1.55 \\
F4 & -5.67 & -3.75 & 1.92 \\
F5 & -5.26 & -3.79 & 1.47 \\
PCBM & -6.01 & -3.83 & 2.18 \\
\hline
\end{tabular}

The use of fullerenes F1, F3, and F4 as acceptor molecules for bulk-heterojunction polymer solar cells was investigated in a preliminary way using $\mathrm{P} 3 \mathrm{HT}$ as donor polymer. However, up to now the highest power conversion efficiency, reached with F4, was $0.46 \%$ only, although acceptable FF (0.30) and $V_{\text {oc }}(0.48$ Volt $)$ were obtained. A wider screening of solvents and thickness in order to optimize morphology and performance is in progress in our laboratories.

\section{Conclusions}

In summary, we have prepared five interesting soluble fulleropyrrolidines and methanofullerenes, bearing one or two terthiophene moieties, as potential acceptors for the creation of efficient bulk-heterojunction solar cells based on donor polymers containing thiophene units. These novel fullerene derivatives are characterized by a better harvesting of the solar radiation with respect to traditional PCBM. In addition, they have a relatively high LUMO level and a low band gap that can be easily tuned by an adequate design of the link between the fullerene and the terthiophene.

Besides, it is worth pointing out that the new fullerene derivatives prepared in the present work are also of interest as new molecular building blocks for materials with nonlinear optical (NLO) properties [38-43]. In particular, because the methanofullerene F4 is an excellent candidate as secondorder NLO chromophore due to the presence of the highly polarizable electron acceptor C60-fullerene system linked to the donor terthiophene through a cyclopropane group, its quadratic hyperpolarizability is under study in our laboratories.

\section{Conflict of Interests}

The authors declare that there is no conflict of interests regarding the publication of this paper.

\section{Acknowledgments}

This work was supported by Eni (Contract no. 3500005452). The authors thank Andrea Alessi (Eni S.p.A.) for the UVvisible analysis and the useful discussion.

\section{References}

[1] M. K. Nazeeruddin, E. Baranoff, and M. Grätzel, "Dye-senstized solar cells: a brief overview," Solar Energy, vol. 85, no. 6, pp. 11721178, 2011.

[2] J.-H. Yum, E. Baranoff, S. Wenger, M. K. Nazeeruddin, and M. Grätzel, "Panchromatic engineering for dye-sensitized solar cells," Energy \& Environmental Science, vol. 4, no. 3, pp. 842-857, 2011.

[3] S. Günes, H. Neugebauer, and N. S. Sariciftci, "Conjugated polymer-based organic solar cells," Chemical Reviews, vol. 107, no. 4, pp. 1324-1338, 2007.

[4] B. Kippelen and J. Brédas, "Organic photovoltaics," Energy and Environmental Science, vol. 2, no. 3, pp. 251-261, 2009.

[5] F. G. Brunetti, R. Kumar, and F. Wudl, "Organic electronics from perylene to organic photovoltaics: painting a brief history with a broad brush," Journal of Materials Chemistry, vol. 20, no. 15, pp. 2934-2948, 2010.

[6] Y. Liang, Z. Xu, J. Xia et al., "For the bright future-bulk heterojunction polymer solar cells with power conversion efficiency of 7.4\%," Advanced Materials, vol. 22, no. 20, pp. E135-E138, 2010.

[7] A. Colombo, C. Dragonetti, D. Roberto et al., "A novel diruthenium acetylide donor complex as an unusual active material for bulk heterojunction solar cells," Organometallics, vol. 30, no. 6 , pp. 1279-1282, 2011.

[8] R. Po, A. Bernardi, A. Calabrese, C. Carbonera, G. Corso, and A. Pellegrino, "From lab to fab: how must the polymer solar cell materials design change? - an industrial perspective," Energy \& Environmental Science, vol. 7, pp. 925-943, 2014.

[9] J. C. Hummelen, B. W. Knight, F. Lepeq, F. Wudl, J. Yao, and C. L. Wilkins, "Preparation and characterization of fulleroid and methanofullerene derivatives," Journal of Organic Chemistry, vol. 60 , no. 8 , pp. 532-538, 1995.

[10] G. Yu, J. Gao, J. C. Hummelen, F. Wudl, and A. J. Heeger, "Polymer photovoltaic cells: Enhanced efficiencies via a network of 
internal donor-acceptor heterojunctions," Science, vol. 270, no. 5243, pp. 1789-1791, 1995.

[11] C. Brabec, A. Cravino, D. Meissner et al., "Origin of the open circuit voltage of plastic solar cells," Advanced Functional Materials, vol. 11, no. 5, pp. 374-380, 2001.

[12] C. Yang, J. Y. Kim, S. Cho, J. K. Lee, A. J. Heeger, and F. Wudl, "Functionalized methanofullerenes used as n-type materials in bulk-heterojunction polymer solar cells and in field-effect transistors," Journal of the American Chemical Society, vol. 130, no. 20, pp. 6444-6450, 2008.

[13] Y. Zhang, H. Yip, O. Acton, S. K. Hau, F. Huang, and A. K.-Y. Jen, "A simple and effective way of achieving highly efficient and thermally stable bulk-heterojunction polymer solar cells using amorphous fullerene derivatives as electron acceptor," Chemistry of Materials, vol. 21, no. 13, pp. 2598-2600, 2009.

[14] M. Lenes, S. W. Shelton, A. B. Sieval, D. F. Kronholm, J. C. Hummelen, and P. W. M. Blom, "Electron trapping in higher adduct fullerene-based solar cells," Advanced Functional Materials, vol. 19, no. 18, pp. 3002-3007, 2009.

[15] T. Niinomi, Y. Matsuo, M. Hashiguchi, Y. Sato, and E. Nakamura, "Penta(organo)[60]fullerenes as acceptors for organic photovoltaic cells," Journal of Materials Chemistry, vol. 19, no. 32, pp. 5804-5811, 2009.

[16] S. Y. Nam, H. S. Lee, J. Jung et al., "Ethyleneoxy substituted methanofullerenes for acceptor materials in organic photovoltaic cells," Journal of Nanoscience and Nanotechnology, vol. 9, no. 12, pp. 7034-7038, 2009.

[17] Y. Matsuo, Y. Sato, T. Niinomi, I. Soga, H. Tanaka, and E. Nakamura, "Columnar structure in bulk heterojunction in solution-processable three-layered $\mathrm{p}$-i-n organic photovoltaic devices using tetrabenzoporphyrin precursor and silylmethyl[60]fullerene," Journal of the American Chemical Society, vol. 131, no. 44, pp. 16048-16050, 2009.

[18] H. Zhao, X. Guo, H. Tian et al., "Alkyl substituted [6,6]-thienyl$\mathrm{C}_{61}$-butyric acid methyl esters: Easily accessible acceptor materials for bulk-heterojunction polymer solar cells," Journal of Materials Chemistry, vol. 20, no. 15, pp. 3092-3097, 2010.

[19] K. Yoshimura, K. Matsumoto, Y. Uetani et al., “Thiophenesubstituted fulleropyrrolidine derivatives as acceptor molecules in a thin film organic solar cell," Tetrahedron, vol. 68, no. 18, pp. 3605-3610, 2012.

[20] L. M. Popescu, P. Van 'T Hof, A. B. Sieval, H. T. Jonkman, and J. C. Hummelen, "Thienyl analog of 1-(3methoxycarbonyl)propyl-1-phenyl-[6,6]- methanofullerene for bulk heterojunction photovoltaic devices in combination with polythiophenes," Applied Physics Letters, vol. 89, no. 21, Article ID 213507, 2006.

[21] P. A. Troshin, H. Hoppe, J. Renz et al., "Material solubilityphotovoltaic performance relationship in the design of novel fullerene derivatives for bulk heterojunction solar cells," Advanced Functional Materials, vol. 19, no. 5, pp. 779-788, 2009.

[22] C. Saravanan, C. Liu, Y. Chang et al., "Fulleropyrrolidines bearing $\pi$-conjugated moiety for polymer solar cells: contribution of the chromophoric substituent on C60 to the photocurrent," ACS Applied Materials and Interfaces, vol. 4, no. 11, pp. 61336141, 2012.

[23] J. J. Kim, H. Choi, J. W. Lee et al., "A polymer gel electrolyte to achieve $\geq 6 \%$ power conversion efficiency with a novel organic dye incorporating a low-band-gap chromophore," Journal of Materials Chemistry, vol. 18, no. 43, pp. 5223-5229, 2008.
[24] X. Zhao, C. Piliego, B. Kim et al., "Solution-processable crystalline platinum-acetylide oligomers with broadband absorption for photovoltaic cells," Chemistry of Materials, vol. 22, no. 7, pp. 2325-2332, 2010.

[25] A. Lembo, P. Tagliatesta, and D. M. Guldi, "Synthesis and photophysical investigation of new porphyrin derivatives with $\beta$-pyrrole ethynyl linkage and corresponding dyad with [60] fullerene," The Journal of Physical Chemistry A, vol. 110, no. 40, pp. 11424-11434, 2006.

[26] I. Jestin, P. Frère, N. Mercier, E. Levillain, D. Stievenard, and J. Roncali, "Synthesis and characterization of the electronic and electrochemical properties of thienylenevinylene oligomers with multinanometer dimensions," Journal of the American Chemical Society, vol. 120, no. 32, pp. 8150-8158, 1998.

[27] P. L. Vidal, B. Divisia-Blohorn, G. Bidan, J. L. Hazemann, J. M. Kern, and J. P. Sauvage, " $\pi$-conjugated ligand polymers entwined around copper centres," Chemistry, vol. 6, no. 9, pp. 1663-1673, 2000.

[28] M. Prato, M. Maggini, C. Giacometti, G. Scorrano, G. Sandonà, and G. Farnia, "Synthesis and electrochemical properties of substituted fulleropyrrolidines," Tetrahedron, vol. 52, no. 14, pp. 5221-5234, 1996.

[29] M. Prato and M. Maggini, "Fulleropyrrolidines: a family of fullfledged fullerene derivatives," Accounts of Chemical Research, vol. 31, no. 9, pp. 519-526, 1998.

[30] J. H. Choi, K. Son, T. Kim, K. Kim, K. Ohkubo, and S. Fukuzumi, "Thienyl-substituted methanofullerene derivatives for organic photovoltaic cells," Journal of Materials Chemistry, vol. 20, no. 3, pp. 475-482, 2010.

[31] J. H. Choi, T. Honda, S. Seki, and S. Fukuzumi, "Relationship between crystal packing and high electron mobility in the single crystal of thienyl-substituted methanofullerene," Chemical Communications, vol. 47, no. 40, pp. 11213-11215, 2011.

[32] J. Lehl and J. Nierengarten, "A click-click approach for the preparation of functionalized [5:1]-hexaadducts of $\mathrm{C}_{60}$," Chemistry A, vol. 15, no. 30, pp. 7306-7309, 2009.

[33] J. Iehl and J. Nierengarten, "Sequential copper catalyzed alkyneazide and thiol-ene click reactions for the multiple functionalization of fullerene hexaadducts," Chemical Communications, vol. 46, no. 23, pp. 4160-4162, 2010.

[34] Y. Liang, Z. Xu, J. Xia et al., "For the bright future-bulk heterojunction polymer solar cells with power conversion efficiency of 7.4\%," Advanced Materials, vol. 22, no. 20, pp. E135E138, 2010.

[35] W. Y. Wong, X. Z. Wang, Z. He et al., "Metallated conjugated polymers as a new avenue towards high-efficiency polymer solar cells," Nature Materials, vol. 6, no. 7, pp. 521-527, 2007.

[36] R. S. Ashraf, M. Shahid, E. Klemm, M. Al-Ibrahim, and S. Sensfuss, "Thienopyrazine-based low-bandgap poly(heteroaryleneethynylene)s for photovoltaic devices," Macromolecular Rapid Communications, vol. 27, no. 17, pp. 1454-1459, 2006.

[37] J. Y. Kim, S. H. Kim, H.-H. Lee et al., "New architecture for high-efficiency polymer photovoltaic cells using solution-based titanium oxide as an optical spacer," Advanced Materials, vol. 18, no. 5, pp. 572-576, 2006.

[38] F. Langa De La Puente and J.-F. Nierengarten, Eds., Fullerenes: Principles and Applications, Royal Society of Chemistry, RSC Nanoscience \& Nanotechnology, Cambridge, UK, 2011. 
[39] Y. Zhao, Y. Shirai, A. D. Slepkov et al., "Synthesis, spectroscopic and nonlinear optical properties of multiple [60]fullereneoligo(p-phenylene ethynylene) hybrids," Chemistry, vol. 11, no. 12, pp. 3643-3658, 2005.

[40] S. Muhammad, K. Fukuda, T. Minami, R. Kishi, Y. Shigeta, and M. Nakano, "Interplay between the diradical character and third-order nonlinear optical properties in fullerene systems," Chemistry, vol. 19, no. 5, pp. 1677-1685, 2013.

[41] A. Valore, M. Balordi, A. Colombo et al., "Novel ruthenium(II) complexes with substituted 1,10-phenanthroline or 4,5-diazafluorene linked to a fullerene as highly active second order NLO chromophores," Dalton Transactions, vol. 39, no. 42, pp. 10314-10318, 2010.

[42] C. Dragonetti, A. Valore, A. Colombo et al., "An investigation on the second-order NLO properties of novel cationic cyclometallated $\operatorname{Ir}(\mathrm{III})$ complexes of the type $\left[\operatorname{Ir}(2 \text {-phenylpyridine })_{2}(9\right.$ $\mathrm{R}-4,5$-diazafluorene $)]^{+}(\mathrm{R}=\mathrm{H}$, fulleridene $)$ and the related neutral complex with the new 9-fulleriden-4-monoazafluorene ligand," Inorganica Chimica Acta, vol. 382, no. 1, pp. 72-78, 2012.

[43] S. Di Bella, C. Dragonetti, M. Pizzotti, D. Roberto, F. Tessore, and R. Ugo, "Coordination and organometallic complexes as second-order nonlinear optical molecular materials," Topics in Organometallic Chemistry, vol. 28, pp. 1-55, 2010. 

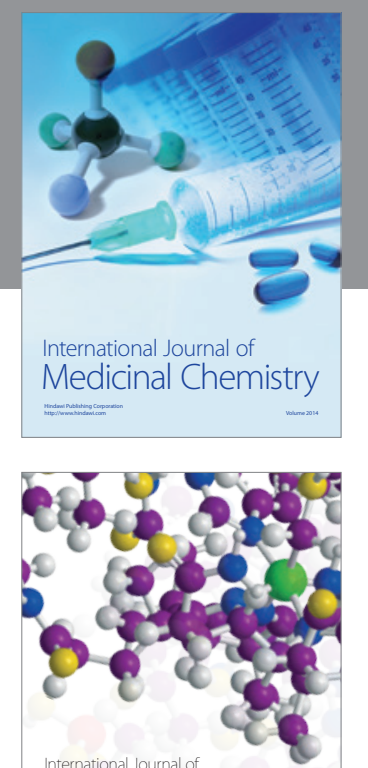

\section{Carbohydrate} Chemistry

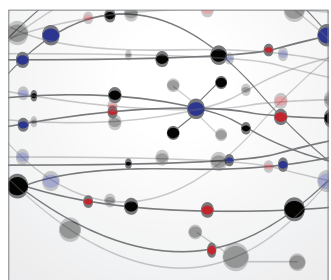

The Scientific World Journal
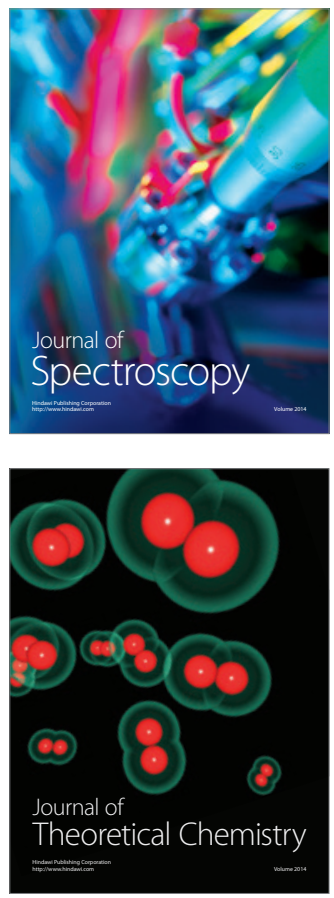
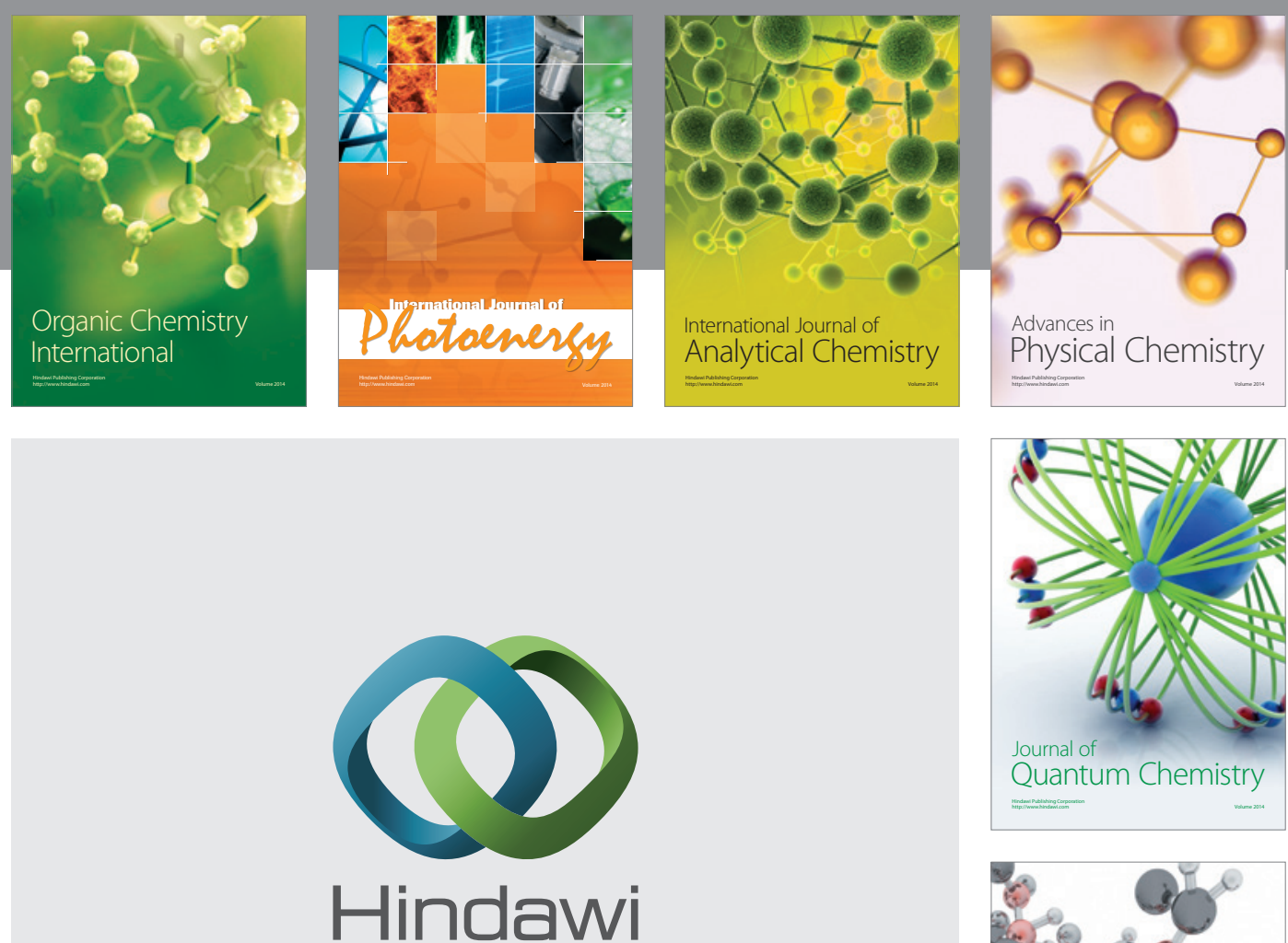

Submit your manuscripts at

http://www.hindawi.com

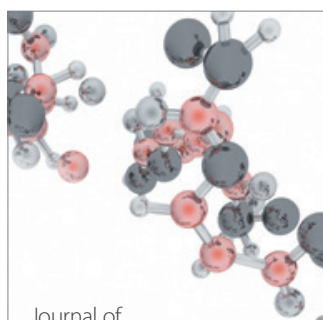

Analytical Methods

in Chemistry

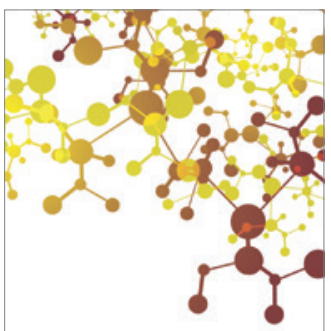

Journal of

Applied Chemistry

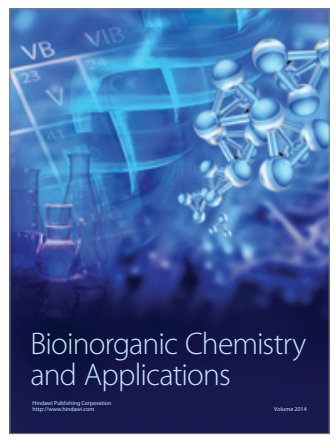

Inorganic Chemistry
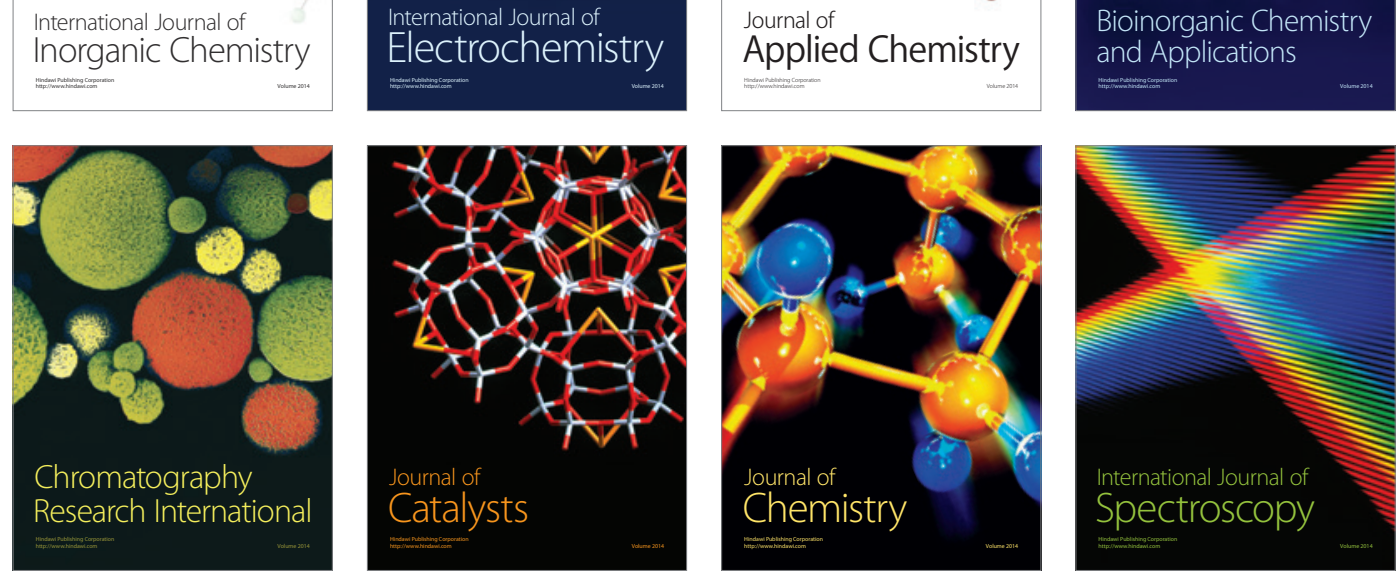